\title{
Adaptação infantil ao tratamento odontológico: relato de caso
}

\section{Child adaptation to dental treatment: a case report}

\author{
Marcieli Dias Furtado* \\ Luiza Beatriz Thurow* \\ Josiane Luzia Dias Damé**** \\ Tania Izabel Bighetti $i^{* * *+}$
}

\section{Resumo}

Na odontopediatria, o ambiente odontológico gera medo e ansiedade, demonstrados de diversas formas pela criança, de modo que há necessidade de promover sua adaptação para que entenda o processo e se sinta parte dele. É importante, ainda, que se identifiquem situações em que o desconforto estético possa gerar constrangimento na convivência diária das crianças. Objetivo: relatar um caso clínico de resolução de comprometimento estético causado por defeito de desenvolvimento do esmalte (DDE) e utilização de técnicas de adaptação de comportamento. Relato de caso: uma paciente do sexo feminino, 3 anos de idade, nascida prematura, apresentava DDE no incisivo central superior esquerdo, que, ao sorrir, cobria com as mãos. O perfil da criança foi avaliado e, a partir das suas características, foram escolhidas as técnicas de dizer-mostrar-fazer, controle de voz, reforço positivo, distração e repetição, usando-as de forma associada para melhores resultados, considerando a necessidade da repetição das visitas ao consultório. Após cinco consultas, foi possível realizar a restauração com resina fotopolimerizável, restabelecendo a estética e o conforto para a criança. Considerações finais: para o atendimento odontológico de crianças, é de fundamental importância conhecer técnicas de manejo infantil e usá-las de acordo com as necessidades individuais, com a finalidade de tornar as crianças participativas no processo, diminuindo a ansiedade, o medo e as reações que podem dificultar ou impedir o atendimento.

Palavras-chave: Comportamento infantil. Dente decíduo. Hipoplasia do esmalte dentário. Odontopediatria.

\section{Introdução}

Alterações dentais ou defeitos de desenvolvimento do esmalte (DDE) nos dentes decíduos ${ }^{1}$ são relacionados principalmente aos incisivos centrais, os dentes mais afetados pelos $\mathrm{DDE}^{2}$. Quando os DDE se apresentam como hipoplasias caracterizadas por perda de esmalte em formato de fóssulas/ fissuras demarcadas, em que os limites são visíveis e em cor bege, amarelada ou marrom ${ }^{2}$, podem trazer desconforto quanto à estética para crianças, gerando tristeza e baixa autoestima ${ }^{3}$, o que também é refletido na percepção dos pais ${ }^{4}$. Essas hipoplasias são uma anormalidade no esmalte do dente que ocorre durante a sua formação $0^{1,5,6}$, podendo apresentar coloração alterada para bege ou marrom, com perdas de estrutura ${ }^{7}$ e com prevalência no sexo feminino ${ }^{1,5}$.

Os DDE se relacionam com diversos fatores, como origem sistêmica, congênita ou alteração local $^{1,5}$. Observa-se, ainda, a associação entre prematuridade e hipoplasia de esmalte em dentes decíduos $^{1,6}$, cabendo a avaliação clínica associada à história de saúde sistêmica do paciente e a eventuais traumas regionais para o diagnóstico de $\mathrm{DDE}^{2}$. Essas alterações, principalmente a hipoplasia, podem prejudicar a dentição da criança, pois apresentam defeito no esmalte, com a formação de nichos que favorecem o acúmulo de biofilme, deixando o dente mais propenso à cárie ${ }^{5,6}$. Em alguns casos, há necessidade de tratar, e para elencar o tratamento adequado de tais anormalidades dentais, deve-se avaliar o tipo presente no paciente, para assim propor a intervenção, que, no geral, envolverá uma abordagem estética ${ }^{6,8}$. No caso da opacidade, pode ser realizada uma microabrasão, já para a hipoplasia, é indicada a restauraçãa $0^{6}$. Para o diagnóstico de tais alterações dentais, é necessário um exame clínico minucioso, acrescido de uma completa anamnese ${ }^{7}$. 
Para realizar os procedimentos odontológicos, há alguns desafios, pois o atendimento à criança, geralmente, é conturbado. $\mathrm{O}$ ambiente em que tais procedimentos acontecem gera medo e ansiedade, demonstrados por meio de recusa ao tratamento, choro, "birra" e, em algumas situações, agressões físicas $^{9,10}$. A fase de vida em que a criança se encontra também é um fator importante, pois tudo é desconhecido ${ }^{11}$. Por essa razão, há necessidade de promover a adaptação da criança ao meio odontológico, de forma que entenda o processo e se sinta parte dele ${ }^{9}$.

Para essa ambientação, na odontopediatria são usadas técnicas como a de dizer-mostrar-fazer, em que se antecede o procedimento com a fala, mostrando como ele será, para depois realizá-lo. Há o controle da voz, em que se usa de entonação e tom para chamar atenção, dar comandos e fazer com que a criança preste atenção no profissional e coopere $^{9,12}$. Também é usual o reforço positivo (social e não social), sendo, nesse caso, utilizado o social, em que a mais simples colaboração da criança é recompensada com elogios, parabenizando-a com alegria para que o comportamento desejado se repita. Outra técnica é a distração, na qual se tira o foco do procedimento, utilizando conversa sobre personagens ou um assunto que chame atenção, como imagens ou histórias. Para o condicionamento do comportamento, também é fundamental a repetição das visitas ao consultório, bem como dos procedimentos ou das conversas, até que a criança se sinta confiante e colabore $^{9,13}$. O vocabulário adaptado e relacionado ao imaginário da criança se torna uma ferramenta de grande valor para comunicação. A conduta do dentista, o vocabulário usado, o modo como compreende seu paciente e se expressa influenciam muito para que o paciente seja receptivo ${ }^{11}$.

Tendo em vista a necessidade de conhecer as técnicas e ampliar seu uso, além de comprovar sua funcionalidade, o presente trabalho tem por objetivo relatar um caso clínico de adaptação de comportamento de uma criança e o tratamento realizado para minimizar o desconforto estético e emocional, que gerava constrangimento na sua convivência diária.

\section{Relato de caso}

Este trabalho faz parte do projeto de pesquisa "Processo de trabalho e saúde bucal de crianças institucionalizadas na Casa da Criança São Francisco de Paula, Pelotas, RS", aprovado pelo Comitê de Ética em Pesquisa da Faculdade de Medicina da Universidade Federal de Pelotas (parecer consubstanciado $\mathrm{n}^{\mathrm{o}} 2.258 .943$, de 07 de setembro de 2017). Os aspectos éticos foram respeitados conforme recomenda a Resolução no 466/2012, do Conselho Nacional de Saúde, de modo que os pais/responsáveis autorizaram fotografias, exames bucais e tratamen- tos odontológicos das crianças durante os procedimentos de matrícula na instituição.

A paciente era uma criança do sexo feminino e nascida prematura, que tinha 3 anos de idade e apresentava o incisivo central superior esquerdo com uma mancha acastanhada e de superfície irregular. Observou-se, na avaliação odontológica, que apenas o incisivo central apresentava lesão não cariosa com degrau na sondagem, de coloração acastanhada e com limites definidos. A partir das informações de que a menina era nascida prematura e que a família não lembrava do aparecimento da lesão, somadas ao exame clínico, chegou-se ao diagnóstico de DDE (Figura 1). Havia relato por parte da família de que a estética era um incômodo para a criança, que, principalmente ao sorrir, cobria os dentes com as mãos. A conduta gerava preocupação aos pais, que também relataram incômodo com a questão estética.

Na tentativa de avaliação, no entanto, a menina se recusava a entrar no consultório odontológico, inviabilizando o atendimento. A idade da criança faz parte da fase descrita por Piaget (1970) como pré-operatória ou simbólica, em que a criança associa as coisas à sua vivência, é um período em que ela usa da imitação (de reproduzir modelos), caracterizado pela necessidade de explicações, conhecida também como a fase dos "porquês". Nesse período, há dificuldade ou inexistência de flexibilidade ou mudanças de ideias, de modo que a criança não entende as palavras por si, ela as associa ao imaginário para compreender ${ }^{14,15}$.

Considerando as características pessoais e as respectivas para a faixa etária, bem como a não urgência do tratamento, que poderia ser protelado por algum tempo, optou-se pela adaptação comportamental, ao invés da contenção física, utilizando os métodos de adaptação comportamental em conjunto. Inicialmente, foram realizadas visitas até a sala de consulta, seguidas de uso da cadeira e da técnica diga-mostre-faça, com objetos de uso cotidiano do consultório, em linguagem adaptada, sempre utilizando o controle da voz e, a cada avanço, o reforço positivo social.

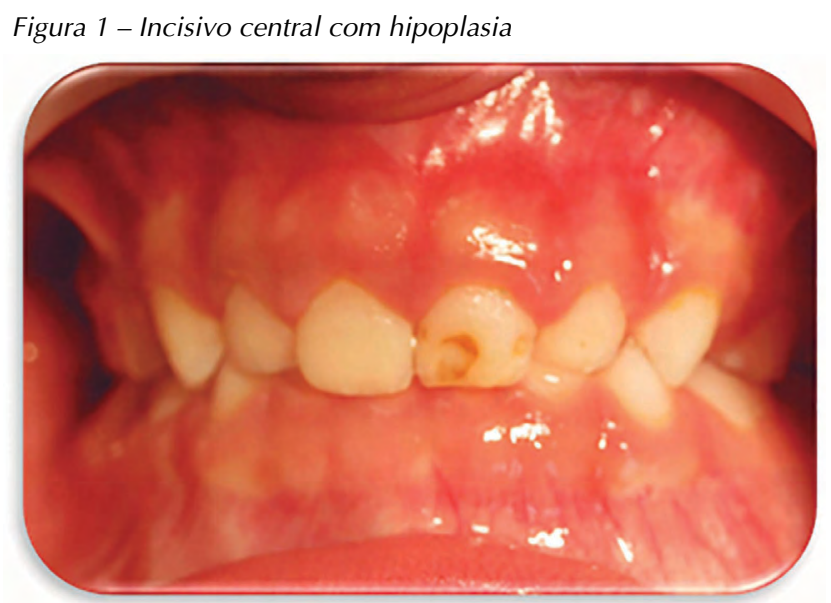

Fonte: autores. 
O primeiro dia em que se realizou a avaliação na paciente foi a pedido dos pais. A menina veio ao consultório no colo, não quis sentar na cadeira odontológica, sempre chorando muito e chamando pela mãe, não se conseguiu nenhum tipo de conversa.

Segundo a versão brasileira da escala de padrão comportamental de Venham (2008), a paciente se encontrava no escore 4, em que o protesto é generalizado $^{16}$. Não há nenhum tipo de cooperação, a criança coloca as mãos sobre a boca inviabilizando o atendimento, sendo necessário o uso da contenção física, tornando impossível o atendimento ${ }^{16}$.

Observada a necessidade do tratamento, primeiramente, optou-se por fazer a adaptação. As visitas ao consultório odontológico aconteciam uma vez na semana, no dia de atendimento odontológico de pré-escola, que ocorre na instituição na qual a criança era assistida. Nesse dia, a menina era chamada na sua sala pela cirurgiã-dentista ou por uma acadêmica de Odontologia que fazia o atendimento e era levada até o consultório odontológico. Durante o trajeto, já era iniciado o processo de diálogo na tentativa de criar o vínculo com a criança.

Dando início à adaptação, o primeiro passo foi tentar um diálogo com a criança, que, após algumas sessões, começou a entrar na sala odontológica caminhando e conversando. Após esse vínculo inicial, ela foi levada até a cadeira odontológica, em que foi deitada. Nesse momento, foi explicado tudo que seria feito no procedimento anteriormente. Primeiro, foi dito que a cadeira iria subir e faria determinado barulho, então a cadeira foi elevada. Depois, foi dito que a cadeira desceria e sem barulho, e assim foi feito. Realizou-se esse processo por duas sessões, ela entrava no consultório, conversava, ia até a cadeira, subia, descia e retornava para a sala. Assim que ela se ambientou ao processo, começou o próximo passo, sempre precedendo com a fala, mostrando algo e depois fazendo na criança, sempre com a utilização de uma linguagem adequada.

Em seguida, a criança foi apresentada à seringa tríplice, chamando de "aguinha" e "ventinho" (Figura 2), que inicialmente foram colocados na mão dela, e depois no dente. Em seguida, foram mostrados o sugador, nomeado de "patinho" (Figura 3), que suga a água, e a caneta de alta rotação, chamada de "chuveirinho", que inicialmente foi apresentada sem a broca, apenas com a água, na mão, e depois para lavar o dente.
Figura 2 - Utilização da seringa tríplice

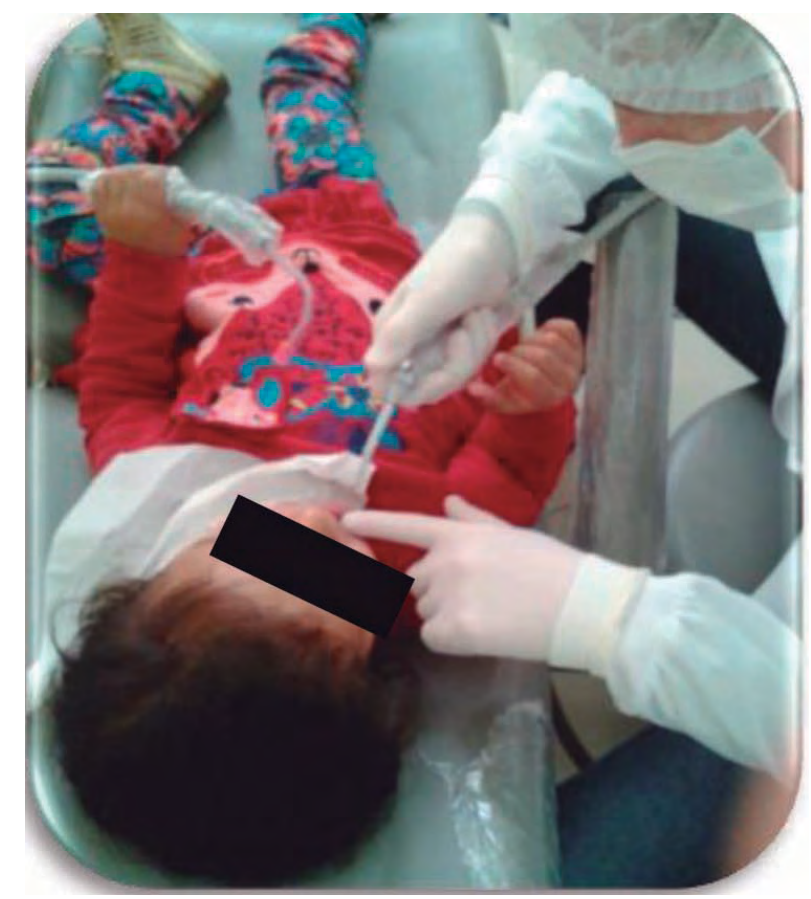

Fonte: autores.

Figura 3 - Familiarização com o sugador

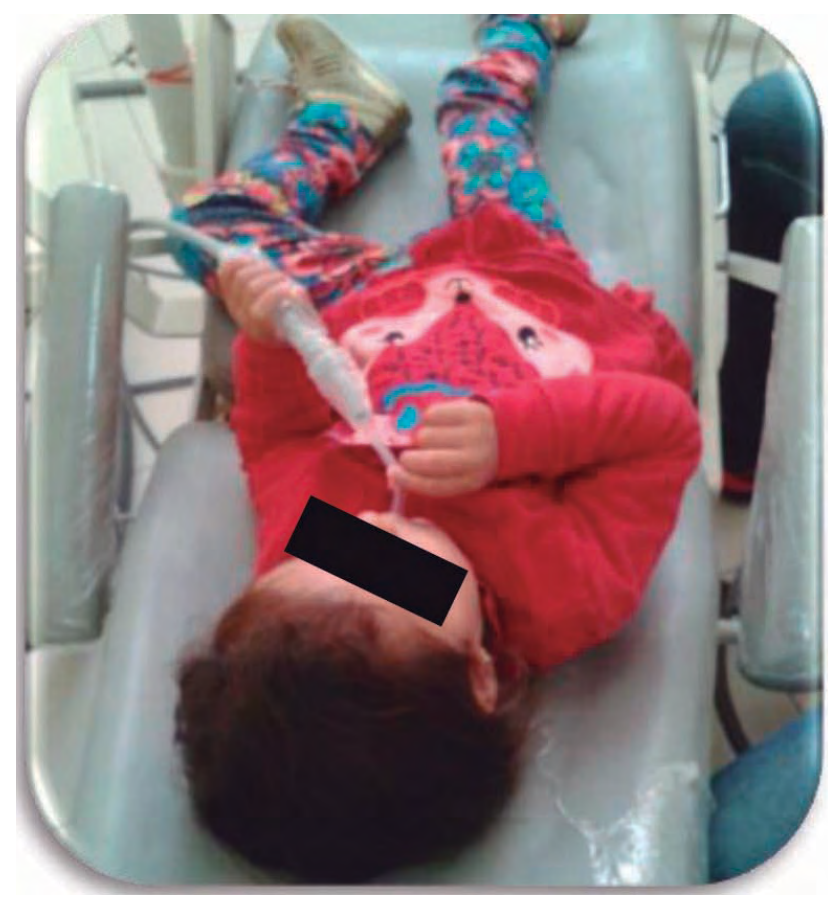

Fonte: autores.

Nessa etapa, quatro consultas foram realizadas, até que ela se acostumasse com os itens e se sentisse confortável com seu uso na cavidade bucal, sempre utilizando um controle de voz, conversas, parabenizando e encorajando a menina em cada passo.

O passo seguinte foi a utilização dos instrumentais, como pinça clínica, sonda exploradora, espelho, espátula de inserção, e dos materiais, como rolos de algodão. Inicialmente, eram repetidos os passos anteriores, como subir a cadeira, colocar o "patinho" 
na boca e lavar o dente com o "chuveirinho". A partir da colaboração da criança, foram apresentados os outros itens, explicando suas funções: a pinça para pegar o algodão, o espelho para ver o "dentinho", a sonda era um "ganchinho" para tocar o dente.

Tal processo era realizado sempre falando, mostrando e, por fim, utilizando na criança. Ela também pegava os itens, explorava e fazia perguntas. Essa adaptação foi repetida em três consultas, até que foi observado que ela respondia positivamente a todos os instrumentos, sentia-se à vontade no consultório e também conversava bastante, respondendo o que era perguntado. Diante disso, foi explicado a ela que no atendimento seguinte seria realizada uma restauração no "dentinho", que as dentistas iriam tapar o "buraquinho" que havia, e ele ficaria "branquinho", e também iriam convidar um "fotógrafo" para registrar tudo o que iria acontecer.

No atendimento seguinte, a criança foi chamada, a bancada foi montada, todos os instrumentais e materiais que seriam utilizados foram apresentados, e a criança pôde tocá-los e explorá-los antes do procedimento (Figuras 4 e 5).

Figura 4 - Manipulação dos instrumentais clínicos

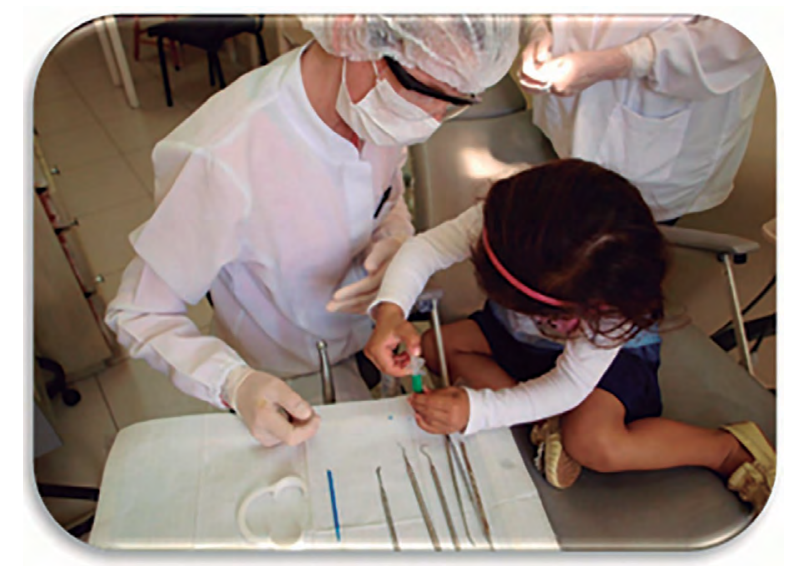

Fonte: autores.

Figura 5 - Manipulação do fotopolimerizador ("luzinha azul")

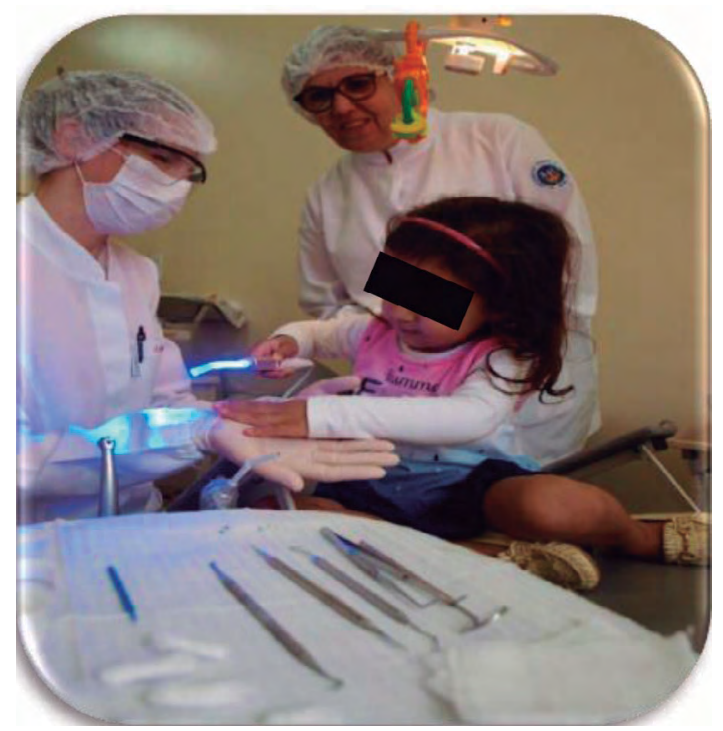

Fonte: autores.
O fotógrafo era um professor do curso de Odontologia, que foi apresentado e pediu para tirar uma fotografia do dente antes de colocar a "massinha", depois, quando o dente ficasse "bem bonito", ele tiraria outra. Para as fotografias, foi utilizado o "afastador labial frontal infantil expandex", cujo nome foi modificado para "sorrisex", e explicado que era para todos os "dentinhos" aparecerem na fotografia. Também foi realizada uma conversa para explicar que o procedimento só aconteceria se ela colaborasse e ajudasse.

A realização da restauração ocorreu com sucesso. Foi necessário envolver uma acadêmica de Odontologia, como operadora, uma cirurgiã-dentista, cuidando do isolamento do campo operatório (sugador e troca de roletes de algodão), e a professora do curso de Odontologia, manipulando os materiais e acompanhando atentamente as reações e os movimentos da criança (Figura 6).

Figura 6 - Atendimento cuidadoso para execução da restauração e para proteção do paciente e da equipe

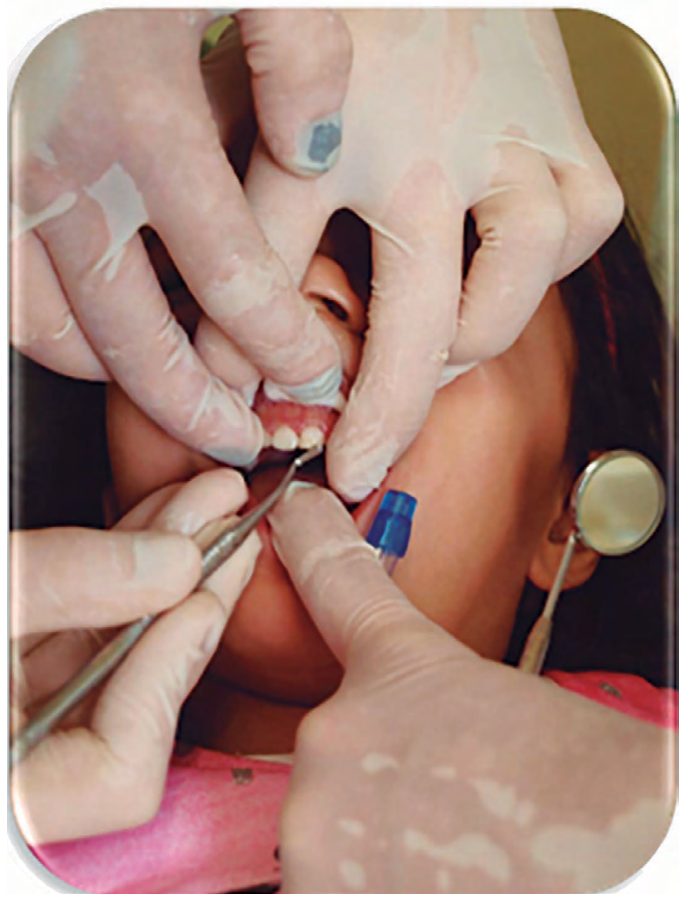

Fonte: autores.

No início e final do procedimento, foram realizadas fotografias (Figura 7), com o objetivo de comparar o antes e o depois do procedimento restaurador, em que foi utilizada uma resina cor B2 para se assemelhar à cor do dente homólogo. 
Figura 7 - Antes e depois do procedimento

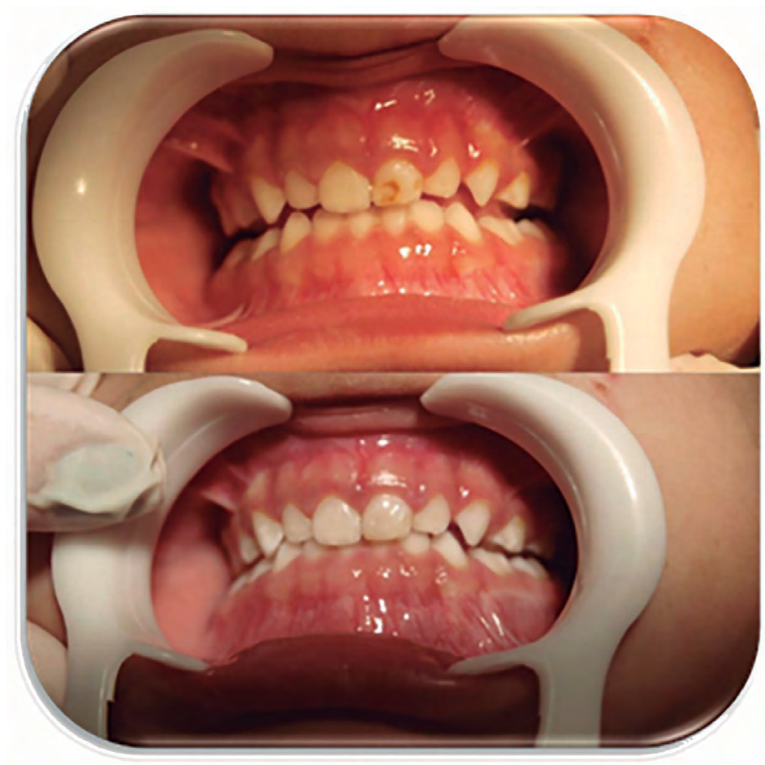

Fonte: autores.

A criança foi monitorada, o que permitiu observar a sua mudança de comportamento (Figura 8), sorrindo após o procedimento e mostrando o "dentinho novo".

Figura 8 - Acompanhamento da criança

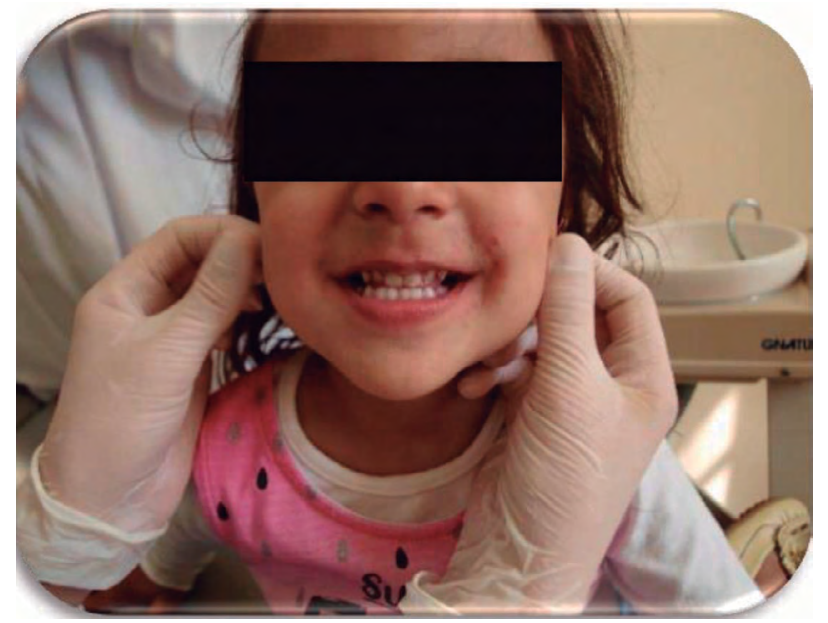

Fonte: autores.

\section{Discussão}

$\mathrm{O}$ atendimento em odontopediatria ocorre de acordo com o comportamento da criança, que é peculiar e diferenciado em cada paciente, podendo ser definido por fatores como idade, cognição, características próprias de humor, medo, ansiedade, vivências e experiências familiares. Pela necessidade de tratamento odontológico em crianças que se recusam ou têm reações adversas, impedindo os procedimentos, o uso das técnicas não farmacológicas (adaptação de comportamento) se torna um auxílio de grande im- portância para o cirurgião-dentista, substituindo o uso de medicações e mantendo a comunicação com a criança ${ }^{11}$. Por essa razão, a adaptação comportamental foi aplicada no presente caso, pois tem como objetivo a comunicação do cirurgião-dentista com a criança, um atendimento com qualidade e o desenvolvimento da relação profissional-paciente, promovendo uma confiança mútua e também a redução do medo e da ansiedade prévios da criança ${ }^{17}$.

Esse momento pode se tornar ainda mais complicado com o despreparo do profissional, pois o manejo comportamental é um processo a ser desenvolvido pelo cirurgião-dentista juntamente com a criança, no qual ela se apropria do mecanismo do atendimento. Com uma comunicação profissional-paciente bem estabelecida e um ambiente acolhedor, pode-se diminuir o medo, a ansiedade e o desconforto nas consultas, e, com isso, a criança vai entender o que será realizado e sua importância ${ }^{17}$. Como cada criança reage de uma forma diferente, quando se pensa na adaptação, devem ser consideradas as particularidades de cada uma e, a partir dessas informações, planejar quais meios e técnicas podem ser usados ${ }^{17,18}$.

No presente trabalho, o perfil da criança foi avaliado com base em seu amadurecimento ${ }^{19} \mathrm{e}$ sua fase de desenvolvimento ${ }^{15}$. A partir das características da paciente, foram escolhidas as técnicas de dizer-mostrar-fazer, em que se usa uma linguagem adequada ao desenvolvimento do paciente ${ }^{9}$, necessária para a situação, pois, aos 3 anos de idade, a criança se encontra no período da imitação $0^{14}$. Assim, a criança ouve o comando do profissional, observa $o$ que ele faz e em seguida reproduz (imitando).

O controle de voz foi escolhido para que a criança prestasse atenção nos comandos e respondesse positivamente, o que pode ser usado com todos os pacientes ${ }^{9,11}$. Essa técnica foi útil para o presente caso porque se precisava chamar a atenção da menina, que necessitava saber o que iria acontecer e o porquê. O reforço positivo social que parabeniza a conduta positiva também pode ser utilizado com qualquer paciente ${ }^{11}$, e foi utilizado com boa resposta pela criança.

A distração também foi utilizada para tirar o foco do procedimento ${ }^{11}$ e para diminuir ansiedade, estresse e rejeição ao tratamento, pois a criança repete o bom comportamento ${ }^{17}$. A utilização desse método foi de grande importância, pois se usou da imaginação da criança, aproveitando que ela se encontrava em uma fase em que se associa a realidade com o imaginário para a compreensão. Logo, ao conversar sobre os desenhos animados e associar o "bicho da cárie" com um vilão, a compreensão do que estava acontecendo foi facilitada. Ainda, foi utilizada a repetição, de modo que, a cada retorno, a criança era estimulada a repetir o comportamento anterior e relembrar os itens já apresentados.

Todos os métodos citados foram usados de forma associada para a obtenção de melhores resultados. 
No passo a passo, a confiança da paciente foi adquirida do ponto zero, pois, no início, não era possível estabelecer nenhuma conversa. Gradativamente, diálogos foram construídos, tanto sobre o atendimento odontológico quanto sobre assuntos do dia a dia da criança, como a cor preferida, o personagem de animação que ela gostava, entre outros.

Assim, a criança foi se ambientando e reagindo positivamente aos métodos usados, houve uma dessensibilização ${ }^{20}$, sempre considerando os limites da paciente ${ }^{19}$, comprovando a efetividade dos métodos de adaptação comportamental bem como a possibilidade de atendimento de crianças que possuem necessidades odontológicas, mas não reagem positivamente no consultório, dispensando o controle por meio farmacológico.

Outro fator importante a ressaltar é que, devido às peculiaridades de cada criança, o tempo necessário para a adaptação pode ser variável e deve ser acompanhado pelo cirurgião-dentista. Não há um plano perfeito, com determinadas consultas, a mudança de comportamento e a perda de ansiedade e medo vão acontecer gradativamente, levando a uma estabilidade emocional, construída juntamente com a confiança entre profissional e paciente, sendo a comunicação o passo inicial.

A utilização de manejo comportamental é fundamental para a formação da relação paciente-dentista, em que a construção da confiança proporciona à criança um autodomínio, no qual a aversão, o temor, a ansiedade e o estresse diminuem ou cessam, a cada progresso ${ }^{19}$.

\section{Conclusão}

Concluiu-se que, para o atendimento odontológico de crianças, é de fundamental importância conhecer técnicas de manejo infantil, para usá-las de acordo com as necessidades individuais dos pacientes, com a finalidade de torná-los participativos no processo, diminuindo a ansiedade, o medo e as reações que podem dificultar ou impedir o atendimento. Cabe acrescentar que o tratamento do DDE foi muito importante, não só pela questão biológica (reduzir o acúmulo de biofilme dentário), mas também pela emocional (minimizar a baixa autoestima da criança).

\section{Abstract}

In pediatric dentistry, the clinical environment generates fear and anxiety, which children show in a number of ways, causing the need to promote their adaptation so they understand the process and feel part of it. It is also important to identify situations in which the aesthetic discomfort may lead to embarrassment in the daily lives of the children. Objective: to report a clinical case of resolution of aesthetic impairment caused by the developmental defect of enamel (DDE) and the use of behavioral adaptation techniques. Case report: female patient, three years old, born premature, presented DDE in the upper left central incisor and, when smiling, covered it with her hands. The profile of the child was evaluated and, based on her characteristics, the techniques of tell-show-do, voice control, positive reinforcement, distraction, and repetition were chosen and used in association for better results, considering the need for repeat visits to the dental office. After five consultations, it was possible to perform the restoration with light-curing resin, restoring the aesthetics and comfort of the child. Final considerations: for the dental care of children, it is essential to know child management techniques and use them according to the individual needs, with the purpose of promoting the participation of the children in the process, decreasing their anxiety, fear, and reactions that may hinder or prevent the treatment.

Keywords: Child behavior. Deciduous teeth. Dental enamel hypoplasia. Pediatric dentistry.

\section{Referências}

1. Barbosa DML, Lemos LVFM, Banzi ÉC de F, Myaki SI. Prevalência de hipoplasia do esmalte em dentes decíduos de crianças nascidas prematuras. Rev Odontol da Unesp 2008; 37(3):261-5.

2. Bogo RB, Sullcahuamán JAG, Ferreira FM, Menezes JVNB, Gugisch RC, Fraiz FC. Prevalência de defeitos de desenvolvimento de esmalte em incisivos permanentes de escolares: estudo fotográfico no sul do Brasil. Rev Odontopediatría Latinoamericana [periódico on-line] 1(1). 2011. [acesso em 19 dez. 2017]. Disponível em URL: https://www.revistaodontopediatria.org/ediciones/2011/1/art-7/.

3. Costa FS, Silveira ER, Pinto GS, Nascimento GG, Thomson WM, Demarco FF. Developmental defects of enamel and dental caries in the primary dentition: a systematic review and meta-analysis. J Dent 2017; 60(1):1-7.

4. Soares FC. Percepção social e autopercepção de crianças de 4 e 5 anos em relação a alterações estéticas no incisivo central decíduo. Diss - Univ Fed St Catarina, Cent Ciências da Saúde Programa Pós-Grad em Odontol [on-line]. 2011. Disponível em URL: https://repositorio.ufsc.br/handle/123456789/95845.

5. Faria PC. Defeitos do esmalte em dentes decíduos: prevalência e fatores associados. Diss Mestr - Curso Pós Grad em Odontol - Univ Fed dos Val do Jequitinhonha e Mucuri [on-line]. 2011; 1-49. Disponível em URL: http://acervo.ufvjm. edu.br/jspui/bitstream/1/464/1/patricia_correa_faria.pdf.

6. Machado AAC, Costa BR, Gomes LRG, Fragelli CMB. Prevalência e etiologia de defeitos de desenvolvimento de esmalte em dentes decíduos e permanentes. Rev Uningá Review 2013; 15(1):48-54.

7. De M, Souchois De Marsillac W, Rodrigues Batista AM, De Oliveira J, De MJ, Rocha C. Alterações na amelogênese e suas implicações clínicas: relatos de casos. Rev Fac Odontol Porto Alegre 2009; 50(1):9-15.

8. Salas MMS, Chisini LA, Castanheira V da S, Castro IS, Teixeira LS, Demarco FF. Defeitos de esmalte não fluoróticos em crianças: aspectos clínicos e epidemiológicos. RFO UPF 2016; 21(2):251-9.

9. Ferreira JMS, Aragão AKR, Colares V. Técnicas de controle do comportamento do paciente infantil: revisão de literatura. Pesq Bras Odontopediatria Clin Integr 2009; 9(2):247-51.

10. Tambellini MM, Gorayeb R. Escalas de medo odontológico em crianças e adolescentes. Rev Paid 2003; 13(26):157-61. 
11. Klatchoian DA, Noronha JC, de Toledo OA. Adaptação comportamental do paciente odontopediátrico. Man Ref para procedimentos clínicos em Odontopediatria/Associação Bras Odontopediatria 2009; 1:49-71.

12. Fernandes L. Técnicas de manejo comportamental não farmacológicas na odontopediatria. Rev Odontol Univ Cid São Paulo 2016; 28(2):135-42.

13. Moraes Albuquerque C, Vinícius C, De Gouvêa D, De Cássia R, Moraes M, Barros RN, et al. Principais técnicas de controle de comportamento em Odontopediatria. Arq em Odontol Fac Odontol Univ Fed Flum [periódico on-line]. 2010; 45(2):110-5. Disponível em URL: http://revodonto.bvsalud. org/pdf/aodo/v46n2/a08v46n2.pdf.

14. Campos CC, Machado GCM, Gonçalves IMF, Amorin LFG, Vieira LAC, Costa LRRS. Clínica odontológica infantil passo a passo. Adaptação do comportamento das crianças em odontologia. Goiânia: UFG/FO; FUNAPE; 2010.

15. Cavicchia DC. O desenvolvimento da criança nos primeiros anos de vida. Acervo digital Unesp [periódico on-line] 2010. Disponível em URL: http://acervodigital.unesp.br/handle/123456789/224.

16. Torriani DD, Teixeira AM, Pinheiro R, Goettems ML, Bonow MLM. Adaptação transcultural de instrumentos para mensurar ansiedade e comportamento em clínica odontológica infantil. Arq Centro Estudos Curso Odontologia 2008; 44(4):17-23.

17. Cortelo FM, Possobon R de F, Costa Junior ÁL, Carrascoza KC. Crianças em atendimento odontológico: arranjos psicológicos para a intervenção. Omnia Saúde 2014; 11(1):1-14.

18. Marques KBG, Gradvohl MPB, Maia MCG. Medo e ansiedade prévios à consulta odontológica em crianças do município de Aracajú-CE. Rev Bras Promoção da Saúde 2010; 23(4):358-67.

19. Ramos-Jorge ML, Paiva SM. Comportamento infantil no ambiente odontológico: aspectos psicológicos e sociais. J Bras Odontopediatria e Odontol do Bebê 2003; 6(29):70-4.

20. Wolf S. Psicologia no consultório odontológico. 2. ed. São Paulo: Arte \& Ciência; 2002. 174 p.

Endereço para correspondência:

Marcieli Dias Furtado

Rua General Marinho da Silva, 557, Bairro Fragata 96045-580, Pelotas, RS, Brasil

Telefone: (53) 999115748

E-mail: mdfurtado@live.com

Recebido: 26/05/18. Aceito: 16/07/18. 